\title{
Highly selective electrochemical fluorination of dithioacetal derivatives bearing electron-withdrawing substituents at the position $\alpha$ to the sulfur atom using poly(HF) salts
}

\author{
Bin Yin, Shinsuke Inagi and Toshio Fuchigami ${ }^{*}$
}

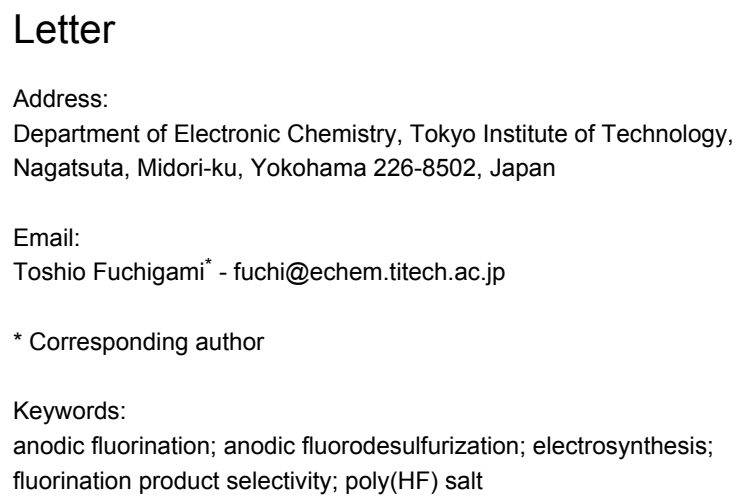

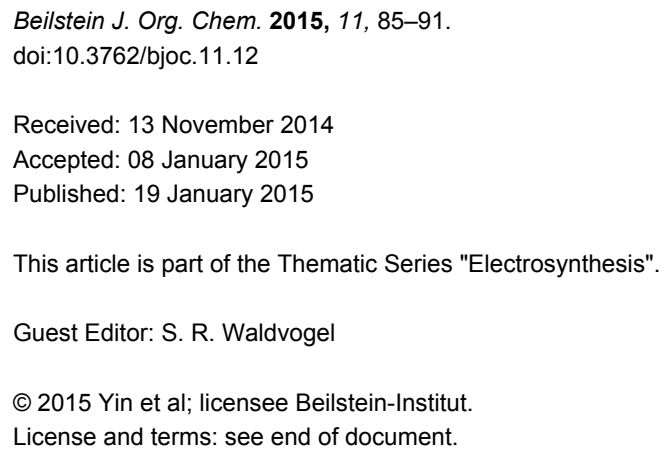

\begin{abstract}
Anodic fluorination of dithioacetals bearing electron-withdrawing ester, acetyl, amide, and nitrile groups at their $\alpha$-positions was comparatively studied using various supporting poly(HF) salts like $\mathrm{Et}_{3} \mathrm{~N} \cdot n \mathrm{HF}(n=3-5)$ and $\mathrm{Et}_{4} \mathrm{NF} \cdot n \mathrm{HF}(n=3-5)$. In the former two cases, the corresponding $\alpha$-fluorination products or fluorodesulfurization products were obtained selectively depending on supporting poly(HF) salts used. In sharp contrast, in the latter two cases, fluorination product selectivity was strongly affected by the electron-withdrawing ability of $\alpha$-substituents: A dithioacetal bearing a relatively weak electron-withdrawing amide group provided a fluorodesulfurization product selectively while a dithioacetal having a strongly electron-withdrawing nitrile group gave the $\alpha$-fluorination product predominantly regardless of the poly(HF) salts used.
\end{abstract}

\section{Introduction}

The introduction of fluorine atom(s) into organic molecules very often improves or enhances their desired characteristic physical and biological properties hence organofluorine compounds are highly useful for medicinal, agrochemical, and materials science [1-6]. In order to prepare new fluorine compounds, selective fluorination of organic compounds is becoming significantly important. Although the selective fluorination has been extensively studied, highly efficient and safe fluorination methods are still demanded $[7,8]$. With these facts in mind, we have developed a selective electrochemical fluorination using ionic liquid poly(HF) salts such as $\mathrm{Et}_{3} \mathrm{~N} \cdot n \mathrm{HF}$ and $\mathrm{Et}_{4} \mathrm{NF} \cdot n \mathrm{HF}(n=3-5)$ as supporting electrolyte and fluorine source [9-11], and we have systematically studied the anodic fluorination of various heteroatom-containing compounds including heterocycles and macromolecules so far [12-20].

More than 20 years ago, we reported the first successful example of the electrochemical selective fluorination of 
heteroatom-containing compounds such as $\alpha$-(phenylthio)ester and its analogues as shown in Scheme 1 [21,22]. Furthermore, anodic fluorodesulfurization of dithioacetals was achieved by direct and indirect anodic oxidation in the presence of the poly(HF) salts [12-16,23-25] or alkali-metal fluorides like KF and CsF with PEG 200 [17]. The anodic fluorination of a dithioacetal derived from an aliphatic aldehyde provided the fluorodesulfurization product while a dithioacetal derived from an aromatic aldehyde provided the $\alpha$-fluorination product (Scheme 2) [25]. These results suggest that the fluorinated product selectivity seems to be controlled by the easiness of the deprotonation of the cationic intermediate A. Namely, since the $\alpha$-proton of the aromatic dithioacetal is more acidic compared to that of an aliphatic dithioacetal, the deprotonation of the former is faster than it is for the latter. Therefore, it can be stated that the product selectivity is controlled by the kinetic acidity of the cationic intermediate A [26,27].

$$
\mathrm{PhS} \widehat{\text { EWG }} \underset{\substack{\mathrm{Et}_{3} \mathrm{~N} \cdot 3 \mathrm{HF} / \mathrm{MeCN} \\ \sim 88 \%}}{\stackrel{-2 \mathrm{e},-\mathrm{H}^{+}}{\mathrm{PhS}}} \overbrace{\mathrm{EWG}}
$$

$\mathrm{EWG}=\mathrm{CF}_{3}, \mathrm{COOEt}, \mathrm{COMe}, \mathrm{CONH}_{2}, \mathrm{P}(\mathrm{O})(\mathrm{OEt})_{2}$

Scheme 1: Anodic fluorination of sulfides having an electron-withdrawing group.

With these facts in mind, we studied comparatively the anodic fluorination of dithioacetal derivatives having various electronwithdrawing groups at their $\alpha$-positions using various poly $(\mathrm{HF})$ salts [28].

\section{Results and Discussion}

Various $\alpha$-substituted methyl phenyl sulfides, 1a, 1c, 1e, and $\mathbf{1 g}$, and their $\alpha$-phenylthio derivatives (dithioacetals) were prepared, and their oxidation potentials $\left(E_{\mathrm{p}}^{\mathrm{ox}}\right)$ were measured by cyclic voltammetry in an anhydrous acetonitrile $(\mathrm{MeCN})$ solution containing $n-\mathrm{Bu}_{4} \mathrm{NBF}_{4}(0.1 \mathrm{M})$ using a platinum disk working electrode and a saturated calomel electrode (SCE) as the reference electrode. All compounds exhibited irreversible multiple oxidation peaks and the first oxidation peak potentials are summarized in Table 1. It was expected that the introduction of an additional phenylthio group to the $\alpha$-position of the sulfides would decrease their oxidation potentials. However, unexpectedly they are higher than those of the corresponding sulfides having a single phenylthio group. Although a detailed reason is not clear at present, the additional phenylthio group does not act as an electroauxiliary, but acts as an electron-withdrawing group. As shown in Table 1, the oxidation potentials of sulfide $1 \mathrm{~g}$ and dithioacetal $\mathbf{1 h}$ having a stronger electron-withdrawing cyano group (Taft $\sigma^{*}=+1.30$ ) [29] are much higher compared to those of $\mathbf{1 a}, \mathbf{1 b}$ with an ester group (Taft $\sigma^{*}=+0.69$ ) [29] and 1c, 1d with an acetyl group (Taft $\sigma^{*}=+0.60$ ) [29], respectively. This indicates that the polar effect, namely electron-withdrawing effect of a substituent greatly affects the electron-transfer step from the substrate to the anode.

Table 1: First oxidation potentials, $E_{\mathrm{p}}^{\mathrm{ox}}$ of compounds 1.<smiles>[R]C([X])Sc1ccccc1</smiles>

\begin{tabular}{llll}
\hline Substrate & $\mathrm{X}$ & $\mathrm{R}\left(\sigma^{*} \text { value }\right)^{\mathrm{a}}$ & $E_{\mathrm{p}}^{\text {ox }}(\mathrm{V} \text { vs SCE })^{\mathrm{b}}$ \\
\hline $\mathbf{1 a}$ & $\mathrm{H}$ & COOEt $(+0.69)$ & 1.60 \\
$\mathbf{1 b}$ & SPh & COOEt $(+0.69)$ & 1.73 \\
$\mathbf{1 c}$ & $\mathrm{H}$ & COMe $(+0.60)$ & 1.59 \\
$\mathbf{1 d}$ & SPh & COMe $(+0.60)$ & 1.63 \\
$\mathbf{1 e}$ & $\mathrm{H}$ & CONEt $_{2}$ & 1.60 \\
$\mathbf{1 f}$ & SPh & CONEt $_{2}$ & 1.64 \\
$\mathbf{1 g}$ & $\mathrm{H}$ & $\mathrm{CN}(+1.30)$ & 1.85 \\
$\mathbf{1 h}$ & SPh & $\mathrm{CN}(+1.30)$ & 2.04
\end{tabular}

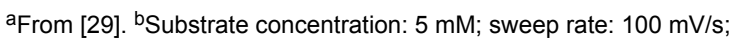
working electrode: Pt disk $(\varnothing=1 \mathrm{~mm})$.

At first, anodic fluorination of ethyl $\alpha, \alpha$-bis(phenylthio)acetate (1b) $[30,31]$ was carried out at platinum plate electrodes in an undivided cell using various solvents in the presence of $\mathrm{Et}_{3} \mathrm{~N} \cdot 3 \mathrm{HF}$ as supporting salt and fluorine source. A constant current was passed until the starting material $\mathbf{1 b}$ was completely consumed (monitored by TLC). As shown in Table 2, the anodic fluorination of $\mathbf{1 b}$ proceeded to give the corresponding

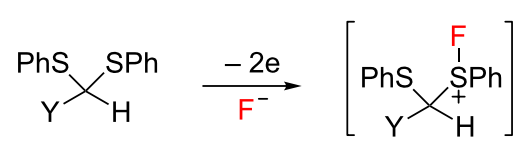

A

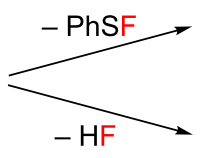

$-\mathrm{HF}$

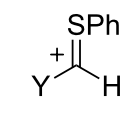

$\underbrace{ \pm}_{Y}$ PhSHP $\stackrel{\mathrm{F}^{-}}{\longrightarrow}$<smiles>[Y]C(F)[SbH2]</smiles>
$Y=$ alkyl

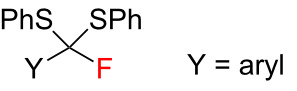


Table 2: Anodic fluorination of $\mathbf{1 b}$ in various solvents containing $\mathrm{Et}_{3} \mathrm{~N} \cdot 3 \mathrm{HF}$.

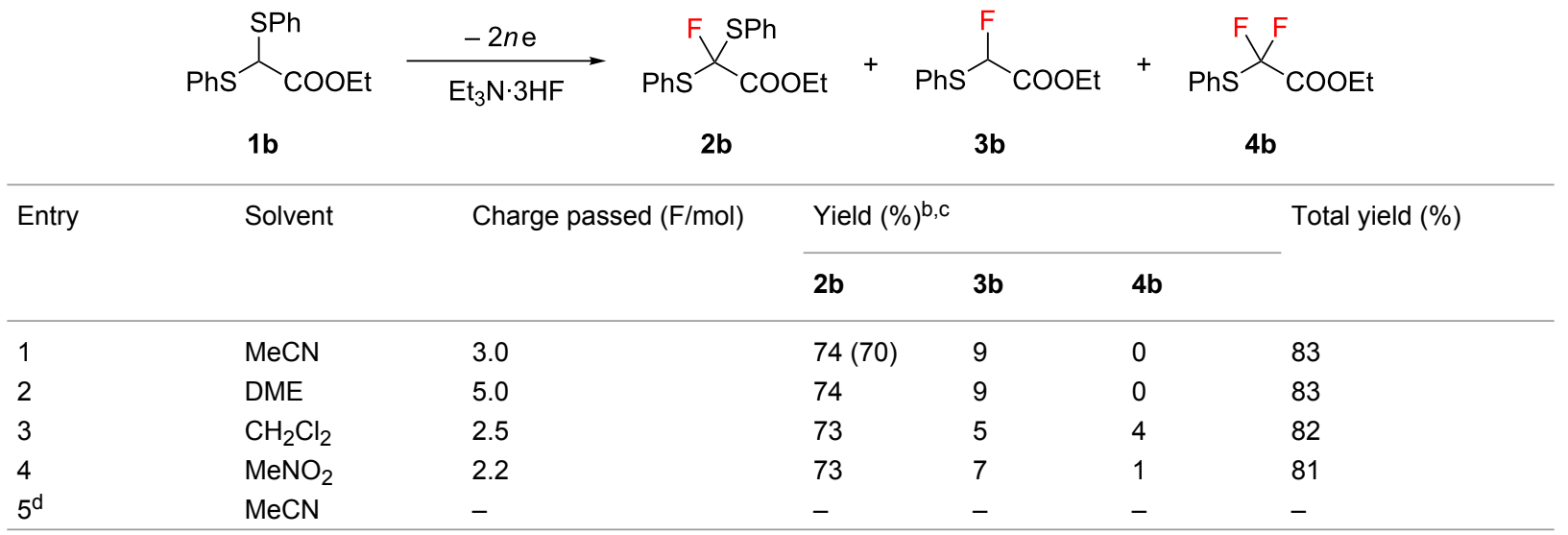

${ }^{a}$ Constant current $\left(8 \mathrm{~mA} / \mathrm{cm}^{2}\right)$ electrolysis was carried out in $0.3 \mathrm{M} \mathrm{Et}_{3} \mathrm{~N} \cdot 3 \mathrm{HF} /$ solvent. ${ }^{\mathrm{b}}$ Determined by ${ }^{19} \mathrm{~F}$ NMR. ${ }^{\mathrm{C}}$ lsolated yield given in parentheses. ${ }^{\mathrm{d}}$ Mechanical stirring was performed overnight at ambient temperature without electrolysis.

$\alpha$-fluoro product $\mathbf{2 b}$ in a good yield regardless of the solvent used. Thus, it was found that the solvents did not affect the yield of $\mathbf{2 b}$ in contrast to the current efficiency. When the reaction was performed in DME as the solvent, anodic decomposition of DME took place simultaneously with the anodic fluorination of $\mathbf{1 b}$, which resulted in low current efficiency. In all cases, fluorodesulfurization product $\mathbf{3 b}$ [22] was detected in considerable yield. When $\mathrm{CH}_{2} \mathrm{Cl}_{2}$ and $\mathrm{MeNO}_{2}$ were used, a small amount of ethyl $\alpha, \alpha$-difluoro- $\alpha$-(phenylthio)acetate (4b) [22] was also detected (Table 2, entries 3 and 4). As a blank test, the electrolytic solution of $\mathbf{1 b}$ was mechanically stirred without electrolysis overnight and $\mathbf{1 b}$ was mostly recovered
(Table 2, entry 5). Therefor electrolysis is necessary for the fluorination to take place.

Among the solvents tested for electrolysis, we decided to use $\mathrm{MeCN}$ for further studies on the anodic fluorination based on a good current efficiency and the formation of only one byproduct.

Next, anodic fluorination of $\mathbf{1 b}$ was carried out in $\mathrm{MeCN}$ using various poly(HF) salts until the substrate was completely consumed and the results are shown in Figure 1. As mentioned earlier, the anodic fluorination of $\mathbf{1 b}$ using $\mathrm{Et}_{3} \mathrm{~N} \cdot 3 \mathrm{HF}$ provided<smiles></smiles>

(a)

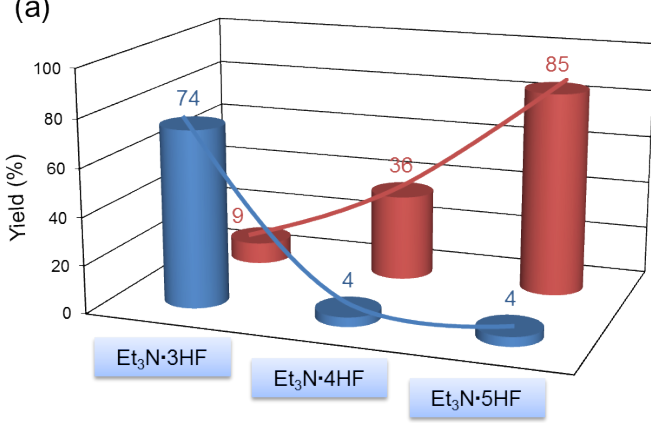

Product 2b

Product $3 b$ (b)

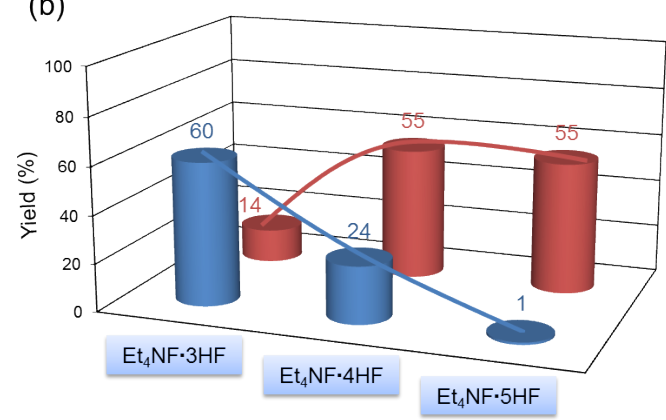

Product 2b

Product 3b

Figure 1: Dependency of fluorinated product selectivity on a series of fluoride salts (a) $\mathrm{Et}_{3} \mathrm{~N} \cdot n \mathrm{HF}(n=3-5)$ and $(\mathrm{b}) \mathrm{Et}{ }_{4} \mathrm{NF} \cdot n \mathrm{HF}(n=3-5)$. 
$\alpha$-fluorinated product $\mathbf{2 b}$ selectively in good yield along with a small amount of fluorodesulfurization product $\mathbf{3 b}$. In contrast, the fluorodesulfurization reaction was significantly promoted with increasing HF content of the poly(HF) salts; especially the use of $\mathrm{Et}_{3} \mathrm{~N} \cdot 5 \mathrm{HF}$ gave predominantly the fluorodesulfurization product $\mathbf{3 b}$ in $85 \%$ yield (Figure 1a). Previously, we obtained 3b in $75 \%$ yield by constant potential anodic oxidation of ethyl $\alpha$-(phenylthio)acetate in a similar electrolytic solution [22]. A comparable dependency of product selectivity on supporting poly(HF) salts was also observed in a series of $\mathrm{Et}_{4} \mathrm{NF} \cdot n \mathrm{HF}$ $(n=3-5)$ although the product yields are moderate (Figure 1b)

According to these results, we carried out the anodic fluorination of other dithioacetals bearing different electron-withdrawing substituents such as acetyl, amide, and cyano groups under similar conditions. The results are summarized in Table 3. In the case of $\alpha, \alpha$-bis(phenylthio)acetone (1d) [32], the use of $\mathrm{Et}_{3} \mathrm{~N} \cdot 3 \mathrm{HF}$ and $\mathrm{Et}_{4} \mathrm{NF} \cdot 3 \mathrm{HF}$ resulted in predominant $\alpha$-fluorination to provide the corresponding monofluorinated product $\mathbf{2 d}$ in good to moderate yields (Table 3, entries 1 and $3)$. On the contrary, when higher HF content salts such as $\mathrm{Et}_{3} \mathrm{~N} \cdot 5 \mathrm{HF}$ and $\mathrm{Et}_{4} \mathrm{NF} \cdot 5 \mathrm{HF}$ were used, fluorodesulfurization product 3d [22] was obtained almost exclusively in moderate or good yield (Table 3, entries 2 and 4). Regardless of poly(HF) salts, difluorinated product 4d [33] was always formed due to the further oxidation of products $\mathbf{2 d}$ and $\mathbf{3 d}$. In contrast, anodic fluorination of $N, N$-diethyl- $\alpha, \alpha$-bis(phenylthio)acetamide (1f) with $\mathrm{Et}_{3} \mathrm{~N} \cdot 3 \mathrm{HF}$ required a large excess amount of electricity to consume the starting substrate 1f, and fluorodesulfurization took place exclusively to provide the corresponding mono- and difluorinated products $3 \mathbf{f}$ and $\mathbf{4 f}[22,34]$ with the same ratio in rather low yields (Table 3, entry 5). The longer electrolysis caused the formation of complicated products. This result is quite different from the case of $\mathbf{1 b}$ and $\mathbf{1 d}$ (Table 2, entry 1 and Table 3, entry 1). Such different anodic behavior may be attributable to different $\mathrm{p} K_{\mathrm{a}}$ values of the $\alpha$-proton of the substrates. It is known that the acidity of the $\alpha$-proton of $N, N$-diethylacetoamide is 4 to 5 times lower than that of acetone and ethyl acetate [35]. Therefore, the acidity of the $\alpha$-proton of $\mathbf{1 f}$ having an amide group would be much lower compared to that of $\mathbf{1 b}$ and 1d having an ester and acetyl group, respectively. Thus, it is reasonable that no deprotonation of the cationic intermediate of 1f took place. Moreover, when a higher HF content poly(HF) salt like $\mathrm{Et}_{3} \mathrm{~N} \cdot 5 \mathrm{HF}$ was used, fluorodesulfurization product $\mathbf{3 f}$ was exclusively formed in good yield. This tendency is quite similar to the result of anodic fluorination of $\mathbf{1 b}$ and $\mathbf{1 d}$ (Figure 1a and Table 3, entries 2 and 4). Thus, it was found that due to the low acidity of the $\alpha$-proton of $\mathbf{1 f}$, fluorodesulfurization took place prior to $\alpha$-fluorination even in the presence of $\mathrm{Et}_{3} \mathrm{~N} \cdot 3 \mathrm{HF}$ containing the free base $\mathrm{Et}_{3} \mathrm{~N}$. In sharp contrast to these cases, $\alpha, \alpha$-bis(phenylthio)acetonitrile (1h) [36] bearing a strongly electron-withdrawing cyano group underwent $\alpha$-fluo-

Table 3: Anodic fluorination of dithioacetal derivative 1 in acetonitrile ${ }^{a}$

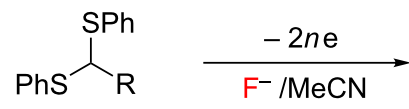

1

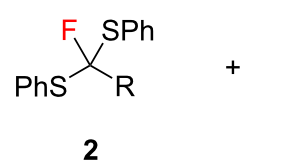

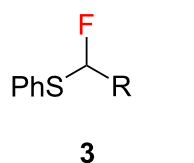

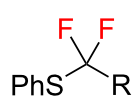

4

\begin{tabular}{|c|c|c|c|c|c|c|}
\hline \multirow[t]{2}{*}{ Entry } & \multirow[t]{2}{*}{$\mathrm{R}$} & \multirow[t]{2}{*}{ Supporting electrolyte } & \multirow[t]{2}{*}{ Charge passed (F/mol) } & \multicolumn{3}{|c|}{ Yield $(\%)^{b, c}$} \\
\hline & & & & 2 & 3 & 4 \\
\hline 1 & COMe (1d) & $\mathrm{Et}_{3} \mathrm{~N} \cdot 3 \mathrm{HF}$ & 3.0 & $80(66)$ & - & 5 \\
\hline 2 & COMe (1d) & $\mathrm{Et}_{3} \mathrm{~N} \cdot 5 \mathrm{HF}$ & 2.5 & - & 63 & 3 \\
\hline 3 & COMe (1d) & $\mathrm{Et}_{4} \mathrm{NF} \cdot 3 \mathrm{HF}$ & 2.7 & 60 & - & 10 \\
\hline 4 & COMe (1d) & $\mathrm{Et}_{4} \mathrm{NF} \cdot 5 \mathrm{HF}$ & 2.5 & 6 & $78(70)$ & 1 \\
\hline 5 & $\mathrm{CONEt}_{2}$ (1f) & $\mathrm{Et}_{3} \mathrm{~N} \cdot 3 \mathrm{HF}$ & 5.0 & 0 & 18 & 17 \\
\hline 6 & CONEt $_{2}(\mathbf{1 f})$ & $\mathrm{Et}_{3} \mathrm{~N} \cdot 5 \mathrm{HF}$ & 3.0 & 0 & $72(63)$ & 1 \\
\hline 7 & $\mathrm{CN}(1 \mathrm{~h})$ & $\mathrm{Et}_{3} \mathrm{~N} \cdot 3 \mathrm{HF}$ & 3.0 & $98(87)$ & 0 & 0 \\
\hline 8 & $\mathrm{CN}(1 \mathrm{~h})$ & $\mathrm{Et}_{3} \mathrm{~N} \cdot 4 \mathrm{HF}$ & 2.8 & 98 & 0 & 0 \\
\hline 9 & $\mathrm{CN}(1 \mathrm{~h})$ & $\mathrm{Et}_{3} \mathrm{~N} \cdot 5 \mathrm{HF}$ & 2.5 & 90 & 0 & 0 \\
\hline 10 & $\mathrm{CN}(1 \mathrm{~h})$ & $\mathrm{Et}_{4} \mathrm{NF} \cdot 3 \mathrm{HF}$ & 2.7 & 94 & 0 & 0 \\
\hline 11 & $\mathrm{CN}(1 \mathrm{~h})$ & $\mathrm{Et}_{4} \mathrm{NF} \cdot 4 \mathrm{HF}$ & 2.5 & 95 & 0 & 0 \\
\hline 12 & $\mathrm{CN}(1 \mathrm{~h})$ & $\mathrm{Et}_{4} \mathrm{NF} \cdot 5 \mathrm{HF}$ & 2.5 & 93 & 0 & 0 \\
\hline
\end{tabular}

${ }^{a}$ Constant current $\left(8 \mathrm{~mA} / \mathrm{cm}^{2}\right)$ electrolysis was carried out using $0.3 \mathrm{M}$ supporting fluoride salt. ${ }^{\mathrm{b}}$ Determined by ${ }^{19} \mathrm{~F}$ NMR. ${ }^{\mathrm{c}} / \mathrm{solated}$ yields are given in parentheses. 
rination exclusively to produce $\alpha$-fluorinated product $\mathbf{2 h}$ in excellent yields regardless of the poly(HF) salts (Table 3 , entries 7-12). In case of $\mathbf{1 h}$, no difluoro product was formed at all, which is probably due to a much higher oxidation potential of $\mathbf{2 h}$ compared to that of the starting substrate $\mathbf{1 h}$. In support of this, we have already shown that introduction of one fluorine atom to the $\alpha$-position of $\alpha$-(phenylthio)acetonitrile increased the oxidation potential by $0.36 \mathrm{~V}$ [22].

A plausible mechanism for the anodic fluorination of dithioacetals $\mathbf{1 b}, \mathbf{1 d}$, and $\mathbf{1 f}$ is shown in Scheme 3. The fluorination reaction is initiated by electron transfer from a sulfur atom of the substrate to generate the corresponding radical cation $\mathbf{B}$, which traps a fluoride ion to afford radical $\mathbf{C}$. This is followed by a further oxidation to give cationic intermediate $\mathbf{D}$. In the cases of $\mathbf{1 b}$ and $\mathbf{1 d}$ having electron-withdrawing ester and acetyl groups, the $\alpha$-protons are acidic enough and can be cleaved by either base, free $\mathrm{Et}_{3} \mathrm{~N}$ (from $\mathrm{Et}_{3} \mathrm{~N} \cdot 3 \mathrm{HF}$ ) [37] or fluoride ions (from $\mathrm{Et}_{4} \mathrm{NF} \cdot 3 \mathrm{HF}$ ). The resulting cation $\mathbf{E}$ reacts with a fluoride ion to form $\mathbf{2 b}$ and $\mathbf{2 d}$. Further anodic fluorodesulfur- ization occurs to provide the corresponding difluorinated products $\mathbf{4 b}$ and $\mathbf{4 d}$, respectively. On the other hand, the desulfurization of intermediate $\mathbf{D}$ followed by reaction with fluoride provides the corresponding fluorodesulfurization products $\mathbf{3 b}$, 3d, and $\mathbf{3 f}$.

When high HF content salts like $\mathrm{Et}_{3} \mathrm{~N} \cdot 5 \mathrm{HF}$ and $\mathrm{Et}_{4} \mathrm{NF} \cdot n \mathrm{HF}$ $(n=4,5)$ are used, the higher concentration of HF in the electrolytic solution would increase the amount of $\mathbf{D}$ rather than $\mathbf{E}$ in an equilibrium between them as shown in Scheme 4. Namely, the deprotonation of $\mathbf{D}$ would be retarded due to high concentration of protons in the solution, and consequently the $\mathrm{C}-\mathrm{S}$ bond cleavage seems to take place more favorably than a deprotonation. A similar effect on the suppression of defluorination of $\mathrm{CF}_{3}$-enolate anion in the presence of a large amount of fluoride ions has been reported [38].

On the other hand, it is known that the acidity of $\alpha$-protons of acetoamides is much lower compared to that of acetate and acetone as mentioned. Therefore, it is understandable that the<smiles>[R]C(Sc1ccccc1)Sc1ccccc1</smiles>

1b: $R=$ COOEt

B

C

1d: $\mathrm{R}=\mathrm{COMe}$

1f : $\mathrm{R}=\mathrm{CONEt}_{2}$

1h: $\mathrm{R}=\mathrm{CN}$<smiles>[R]C(Sc1ccccc1)[S+](F)c1ccccc1</smiles>

D 1d $\left[\mathrm{Et}_{3} \mathrm{~N} \cdot 3 \mathrm{HF} ; \mathrm{Et}_{4} \mathrm{NF} \cdot 3 \mathrm{HF}\right]$

$1 \mathrm{~h}$

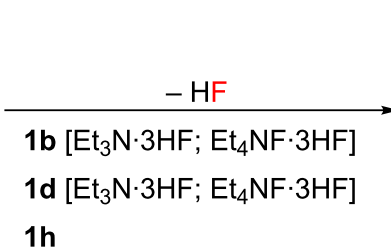
$-\operatorname{PhSF} \mid \begin{aligned} & \text { 1b }\left[\mathrm{Et}_{3} \mathrm{~N} \cdot 5 \mathrm{HF}, \mathrm{Et}_{4} \mathrm{NF} \cdot n \mathrm{HF}(n=4,5)\right] \\ & \text { 1d }\left[\mathrm{Et}_{3} \mathrm{~N} \cdot 5 \mathrm{HF} ; \mathrm{Et}_{4} \mathrm{NF} \cdot 5 \mathrm{HF}\right] \\ & \text { 1f }\left[\mathrm{Et}_{3} \mathrm{~N} \cdot 3 \mathrm{HF}, \mathrm{Et}_{3} \mathrm{~N} \cdot 5 \mathrm{HF}\right]\end{aligned}$<smiles>[R]C=S(C)c1ccccc1</smiles>
F

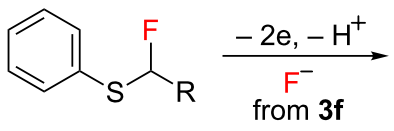

3b: $\mathbf{R}=$ COOEt

3d: $R=C O M e$

3f: $\mathrm{R}=\mathrm{CONEt}_{2}$<smiles>[R]/C(Sc1ccccc1)=[SH]/c1ccccc1</smiles>

E<smiles>CCOC(=O)C(F)(F)Sc1ccccc1</smiles>

$4 f$<smiles>[R]C(F)(Sc1ccccc1)Sc1ccccc1</smiles>

2b: $R=$ COOEt

2d: $R=$ COMe

2h: $\mathrm{R}=\mathrm{CN}$<smiles></smiles><smiles>[R]C(F)(F)Sc1ccccc1</smiles>

4b: $R=$ COOEt

4d: $\mathrm{R}=\mathrm{COMe}$ 


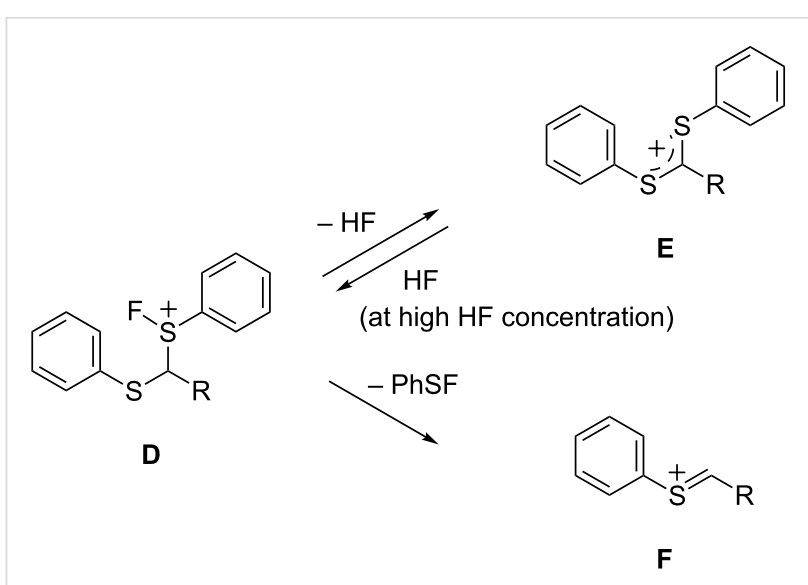

Scheme 4: Mechanism for suppression of the elimination of HF (deprotonation) and preferable desulfurization of $\mathbf{D}$ at high concentrations of $\mathrm{HF}$ in an electrolytic solution.

anodic fluorination of $\mathbf{1 f}$ having a weakly electron-withdrawing amide group resulted in fluorodesulfurization to provide $\mathbf{3 f}$ even when $\mathrm{Et}_{3} \mathrm{~N} \cdot 3 \mathrm{HF}$ containing free base, $\mathrm{Et}_{3} \mathrm{~N}$ was used. As mentioned, the yield of monofluorodesulfurization product $\mathbf{3 f}$ increased markedly by using high $\mathrm{HF}$ content salt, $\mathrm{Et}_{3} \mathrm{~N} \cdot 5 \mathrm{HF}$.

In sharp contrast, in the case of substrate $\mathbf{1 h}$ having a cyano group, $\alpha$-fluorination without desulfurization always took place even when $\mathrm{Et}_{3} \mathrm{~N} \cdot 5 \mathrm{HF}$ and $\mathrm{Et}_{4} \mathrm{NF} \cdot 5 \mathrm{HF}$ were used. This can be explained in terms of fast deprotonation of cationic intermediate $\mathbf{D}$ promoted by a strongly electron-withdrawing cyano group as shown in Scheme 3.

\section{Conclusion}

The regioselective anodic fluorination of ethyl $\alpha, \alpha$ bis(phenylthio)acetate and its acetone, acetoamide, and acetonitrile analogues was successfully carried out using various poly(HF) salts such as $\mathrm{Et}_{3} \mathrm{~N} \cdot n \mathrm{HF}$ and $\mathrm{Et}_{4} \mathrm{NF} \cdot n \mathrm{HF}(n=3-5)$ to provide $\alpha$-fluoro and/or fluorodesulfurization products. The fluorinated product selectivity was found to depend on substituents and supporting poly(HF) salts. The unique product selectivity was tentatively explained in terms of electron-withdrawing ability (Taft $\sigma^{*}$ ) of substituents and HF content of the used supporting poly(HF) salts.

\section{Supporting Information}

\section{Supporting Information File 1}

General methods, synthetic procedures, characterzation data of all new compounds including copies of ${ }^{1} \mathrm{H}$ NMR,

${ }^{13} \mathrm{C}$ NMR and ${ }^{19} \mathrm{~F}$ NMR spectra.

[http://www.beilstein-journals.org/bjoc/content/ supplementary/1860-5397-11-12-S1.pdf]

\section{Acknowledgements}

We gratefully acknowledge Morita Chemical Industries Co., Ltd for supplying triethylamine poly(hydrogen fluoride) $\left[\mathrm{Et}_{3} \mathrm{~N} \cdot n \mathrm{HF}(n=3-5)\right]$ and tetraethylammonium fluoride poly(hydrogen fluoride) $\left[\mathrm{Et}_{4} \mathrm{NF} \cdot n \mathrm{HF}(n=3-5)\right]$ that were used as supporting salt fluorine source. We also thank technical staffs working at Center for Advanced Materials Analysis (Suzukakedai Campus) of Tokyo Institute of Technology for analyzing new compounds. One of the authors (Y. B.) acknowledges Ministry of Education, Culture, Sports, Science \& Technology of Japan for awarding national scholarship to conduct this research.

\section{References}

1. Ojima, I. Fluorine in Medicinal Chemistry and Chemical Biology; Wiley: Chichester, 2009. doi:10.1002/9781444312096

2. Purser, S.; Moore, P. R.; Swallow, S.; Gouverneur, V. Chem. Soc. Rev. 2008, 37, 320-330. doi:10.1039/b610213c

3. Bégué, J.-P.; Bonnet-Delpon, D. Bioorganic and Medicinal Chemistry of Fluorine; John Wiley \& Sons, Inc.: Hoboken, 2008. doi:10.1002/9780470281895

4. Uneyama, K. Organofluorine Chemistry; Blackwell Publishing: Oxford, 2006. doi:10.1002/9780470988589

5. O'Hagen, D. J. Fluorine Chem. 2010, 131, 1071-1081. doi:10.1016/j.jluchem.2010.03.003

6. Hiyama, T., Ed. Organofluorine Compounds. Chemistry and Applications; Springer: Berlin, 2000. doi:10.1007/978-3-662-04164-2

7. Umemoto, T.; Singh, R. P.; Xu, Y.; Saito, N. J. Am. Chem. Soc. 2010, 132, 18199-18205. doi:10.1021/ja106343h

8. Kishi, Y.; Inagi, S.; Fuchigami, T. Eur. J. Org. Chem. 2009, 103-109. doi:10.1002/ejoc.200800872

9. Fuchigami, T.; Atobe, M.; Inagi, S. Fundamental and Applications of Organic Electrochemistry. Synthesis, Materials, Devices; Wiley: Chichester, 2014.

10. Fuchigami, T. In Organic Electrochemistry, 4th ed.; Lund, $\mathrm{H}$.; Hammerich, O., Eds.; Marcel Dekker: New York, 2001; Chapter 25.

11. Childs, W. V.; Christensen, L.; Klink, F. W. In Organic Electrochemistry, 3rd ed.; Lund, H.; Baizer, M. M., Eds.; Marcel Dekker: New York, 1991; Chapter 24.

12. Sawamura, T.; Kuribayashi, S.; Inagi, S.; Fuchigami, T. Org. Lett. 2010, 12, 644-646. doi:10.1021/ol9028836

13. Sawamura, T.; Kuribayashi, S.; Inagi, S.; Fuchigami, T. Adv. Synth. Catal. 2010, 352, 2757-2760. doi:10.1002/adsc. 201000501

14. Fuchigami, T.; Inagi, S. Chem. Commun. 2011, 47, 10211-10223. doi:10.1039/C1CC12414E

15. Takahashi, K.; Furusawa, T.; Sawamura, T.; Kuribayashi, S.; Inagi, S.; Fuchigami, T. Electrochim. Acta 2012, 77, 47-53. doi:10.1016/j.electacta.2012.05.049

16. Takahashi, K.; Inagi, S.; Fuchigami, T. J. Electrochem. Soc. 2013, 160, G3046-G3052. doi:10.1149/2.005307jes

17. Sawamura, T.; Takahashi, K.; Inagi, S.; Fuchigami, T. Angew. Chem., Int. Ed. 2012, 51, 4413-4416. doi:10.1002/anie. 201200438

18. Inagi, S.; Hayashi, S.; Fuchigami, T. Chem. Commun. 2009, 1718-1720. doi:10.1039/B822510A 
19. Hayashi, S.; Inagi, S.; Fuchigami, T. Macromolecules 2009, 42, 3755-3760. doi:10.1021/ma900358x

20. Shaaban, M. R.; Ishii, H.; Fuchigami, T. J. Org. Chem. 2000, 65, 8685-8689. doi:10.1021/jo001129u

21. Fuchigami, T.; Shimojo, M.; Konno, A.; Nakagawa, K. J. Org. Chem. 1990, 55, 6074-6075. doi:10.1021/jo00312a006

22. Fuchigami, T.; Shimojo, M.; Konno, A. J. Org. Chem. 1995, 60, 3459-3464. doi:10.1021/jo00116a037

23. Fuchigami, T.; Sano, M. J. Electroanal. Chem. 1996, 414, 81-84. doi:10.1016/0022-0728(96)04642-6

24. Fuchigami, T.; Mitomo, K.; Ishii, H.; Konno, A. J. Electroanal. Chem. 2001, 507, 30-33. doi:10.1016/S0022-0728(01)00440-5

25. Yoshiyama, T.; Fuchigami, T. Chem. Lett. 1992, 21, 1995-1998. doi:10.1246/cl.1992.1995

26. Yoon, U. C.; Mariano, P. S. Acc. Chem. Res. 1992, 25, 233-240. doi:10.1021/ar00017a005

27. Fuchigami, T.; Ichikawa, S. J. Org. Chem. 1994, 59, 607-615. doi:10.1021/jo00082a018

28. Preliminary results of this work were presented at 225th ECS Meeting, 2014, Abstr. No. 820.

29. Hansch, C.; Leo, A.; Taft, R. W. Chem. Rev. 1991, 91, 165-195. doi:10.1021/cr00002a004

30. Tabti, B.; Gourmala, C.; Bounouara Bouderba, H.; Mulengi, J. K. J. Soc. Alger. Chim. 1996, 6, 199-206.

31. Ritter, R. H.; Cohen, T. J. Am. Chem. Soc. 1986, 108, 3718-3725. doi:10.1021/ja00273a028

32. Keiko, N. A.; Funtikova, E. A.; Stepanova, L. G.; Chuvashev, Yu. A.; Larina, L. I. Russ. J. Org. Chem. 2002, 38, 970-976. doi:10.1023/A:1020893310626

33. Gouault, S.; Guérin, C.; Lemoucheux, L.; Lequeux, T.; Pommelet, J.-C. Tetrahedron Lett. 2003, 44, 5061-5064. doi:10.1016/S0040-4039(03)01134-1

34. Yagupolski, L.; Korinko, V. A. Zh. Obshch. Khim. 1969, 39, 1747.

35. McMurry, J. E.; Simanek, E. E. Fundamentals of Organic Chemistry, 6th ed.; Brooks-Cole Publishing Co, 2006; Chapter 11.

36. Ishibashi, H.; Okada, M.; Sato, K.; Ikeda, M.; Ishiyama, K.; Tamura, Y. Chem. Pharm. Bull. 1985, 33, 90-95. doi:10.1248/cpb.33.90

37. Hou, Y.; Higashiya, S.; Fuchigami, T. J. Org. Chem. 1999, 64, 3346-3349. doi:10.1021/jo981979y

38. Ishikawa, N.; Yokozawa, T. Bull. Chem. Soc. Jpn. 1983, 56, 724-726. doi:10.1246/bcsj.56.724

\section{License and Terms}

This is an Open Access article under the terms of the Creative Commons Attribution License

(http://creativecommons.org/licenses/by/2.0), which permits unrestricted use, distribution, and reproduction in any medium, provided the original work is properly cited.

The license is subject to the Beilstein Journal of Organic Chemistry terms and conditions:

(http://www.beilstein-journals.org/bjoc)

The definitive version of this article is the electronic one which can be found at:

doi:10.3762/bjoc. 11.12 